\title{
Acute Myocardial Infarction following Sildenafil Intake in a Nitrate-Free Patient without Previous History of Coronary Artery Disease
}

\author{
S. Hayat ${ }^{a} \quad$ M. Al-Mutairy ${ }^{a} \quad$ M. Zubaid ${ }^{b} \quad$ C. Suresh ${ }^{b}$ \\ ${ }^{a}$ Department of Medicine and ${ }^{b}$ Division of Cardiology, Mubarak Al-Kabeer Hospital, Kuwait
}

\section{Key Words}

Sildenafil $\cdot$ Nitrate $\cdot$ Myocardial infarction

\begin{abstract}
Objective: To report the occurrence of acute myocardial infarction (MI) associated with the intake of oral sildenafil (Viagra) in a nitrate-free patient without previous history of coronary artery disease. Case Presentation and Intervention: $A$ 50-year-old manual laborer was admitted to the hospital with acute inferoposterior wall $\mathrm{Ml}$ occurring approximately $30 \mathrm{~min}$ after taking oral sildenafil $50 \mathrm{mg}$. This occurred before any attempted sexual activity. Subsequent angiography showed a $70 \%$ stenotic lesion in the midsegment of the dominant circumflex artery. The Naranjo scale indicated that sildenafil was a probable cause of MI. Conclusion: This report shows a rare sildenafil-associated $\mathrm{MI}$ in a nitrate-free patient without a previous history of coronary artery disease.
\end{abstract}

Copyright $\odot 2007$ S. Karger AG, Basel

\section{Introduction}

Sildenafil is an oral phosphodiesterase type 5 (PDE5) inhibitor used for the treatment of impotence. Pooled data regarding myocardial infarction (MI) and cardiovascular death from more than 120 placebo-controlled clinical trials of sildenafil citrate conducted from 1993 to 2001 have shown that the rate of MI or cardiovascular death is 0.91 per 100 person-years (PY) of follow-up among sildenafil-treated patients compared with 0.84 per 100 PY of follow-up among placebo-treated patients [1]. A recent study showed that only 69 acute MIs have been observed during more than 11,000 PY of exposure to sildenafil, with the relative risk for $\mathrm{MI}$ being 0.80 and 0.79 within 24 and $6 \mathrm{~h}$ after taking sildenafil, respectively, the mean time between the last dose of sildenafil and the onset of MI being $14 \pm 2.9$ days [2]. Furthermore, it is notable that sildenafil-associated MI is rarely seen in patients without previous history of coronary artery disease [3]. We report 1 such case.

\section{Case Report}

A 50-year-old man presented to the emergency room with a 1-hour history of left-sided chest pain radiating to the left arm. It was associated with flushing, sweating and vomiting. The symptoms started approximately $30 \mathrm{~min}$ after self-administration of one 50-mg tablet of sildenafil obtained from a friend, before any attempt at sexual intercourse. The patient did not have erectile dysfunction and had never used sildenafil before. He gave a history of hubble-bubble smoking for the last 20 years. He had no other cardiovascular risk factors and his past medical history was unremarkable.

On admission, his blood pressure was $80 / 54 \mathrm{~mm} \mathrm{Hg}$ and pulse was $60 \mathrm{bpm}$. The initial electrocardiogram (ECG) (fig. 1) showed a sinus rhythm of $55 / \mathrm{min}$ with $0.5-\mathrm{mm}$ ST elevation in leads III and aVF, and minimal ST depression in leads V2 toV6. At this point his serum creatinine kinase $(\mathrm{CK})$ level was normal at

\section{KARGER}

Fax +4161306 1234

E-Mail karger@karger.ch

www.karger.com
(C) 2007 S. Karger AG, Basel

$1011-7571 / 07 / 0163-0234 \$ 23.50 / 0$

Accessible online at:

www.karger.com/mpp
Dr. S. Hayat

Department of Medicine

Mubarak Al-Kabeer Hospital (Kuwait)

Mobile +965 767 8600, Fax +965 531 1430, E-Mail ht_sawsan@hotmail.com 
Fig. 1. The initial ECG showing sinus rhythm of $55 / \mathrm{min}$ with $0.5-\mathrm{mm}$ ST elevation in leads III and aVF, and minimal ST depression in leads V2 to V6.

Fig. 2. ECG at $2 \mathrm{~h}$ after admission showing significant ST depression in leads I, aVL and V2 to V6 and ventricular ectopics.

Fig. 3. ECG at $8 \mathrm{~h}$ after admission showing development of Q waves in leads III and aVF indicating inferior MI, and a predominant $\mathrm{R}$ in $\mathrm{V} 2$ with peaked upright $\mathrm{T}$ waves in the right precordial leads consistent with a true posterior MI.
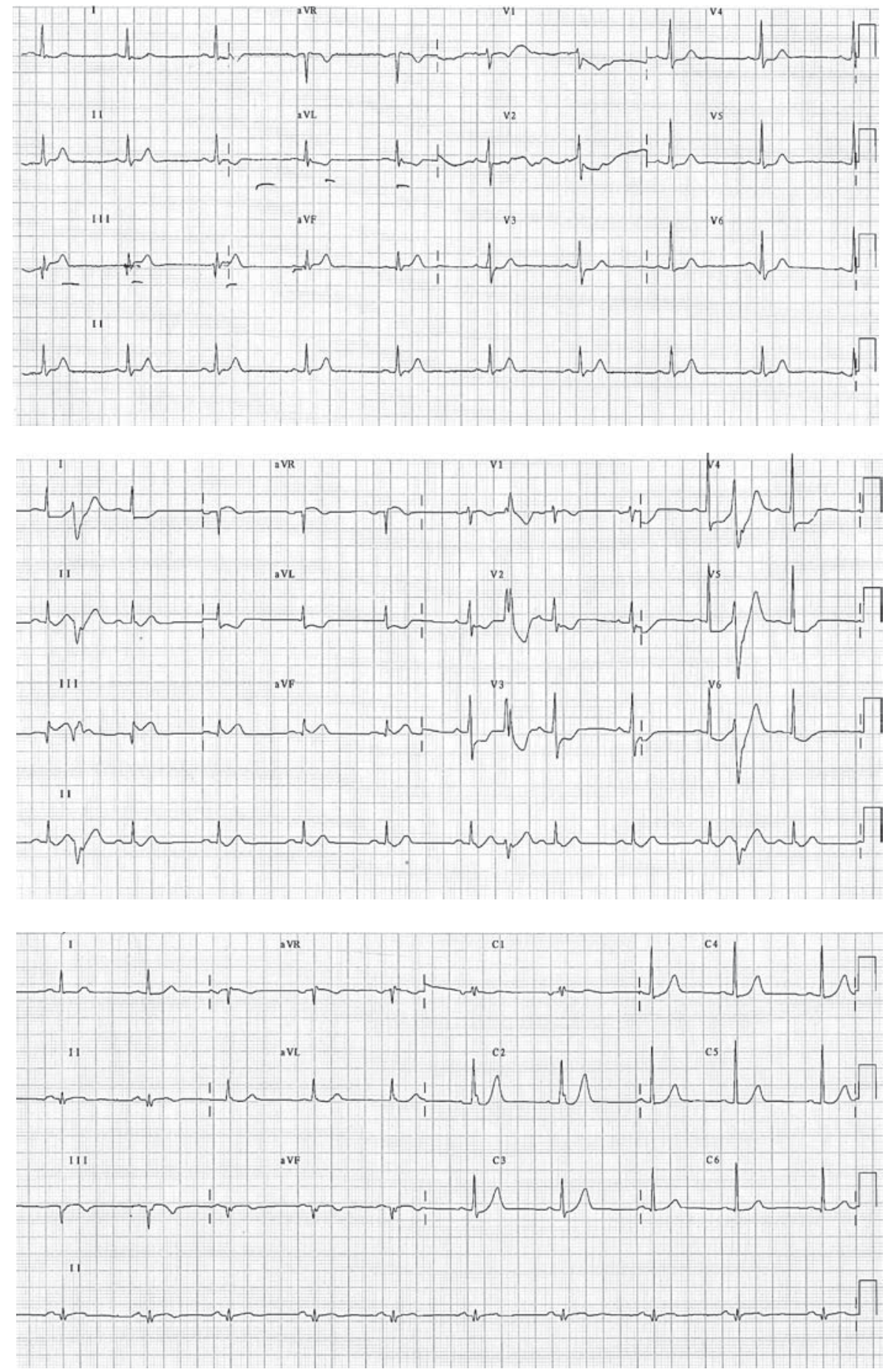

123 IU/1 (22-269). A diagnosis of acute coronary syndrome was made and the patient was started on unfractionated heparin, aspirin, atorvastatin and metoprolol. Two hours after admission, the ECG (fig. 2) showed significant ST depression in leads I, aVL and V2 toV6. Ventricular ectopics were also seen.

In view of ongoing chest pain and significant ST depression on ECG, the patient was started on tirofiban (Aggrastat). Subse- quent CK and CK-MB evaluations peaked at 5,407 and $207 \mathrm{IU} / \mathrm{l}$, respectively, and the troponin level was $22.42 \mathrm{ng} / \mathrm{ml}(<0.10)$. His serum cholesterol was $5.1 \mathrm{mmol} / \mathrm{l}(3.0-5.2)$ and triglycerides were $1.35 \mathrm{mmol} / \mathrm{l}(0.0-2.0)$. Eventually, the patient developed Q waves in leads III and aVF indicating inferior MI, and a predominant $\mathrm{R}$ in V2 with peaked upright $\mathrm{T}$ waves in the right precordial leads consistent with a true posterior MI (fig. 3). 
Two weeks later, he underwent cardiac catheterization, which revealed a $70 \%$ stenotic lesion in the midsegment of the dominant circumflex artery. This was dilated with a balloon, and a $3.5 \times$ $20 \mathrm{~mm}$ stent was implanted.

\section{Discussion}

It has been shown that sildenafil is not associated with a short-term risk for MI and there is a growing body of evidence demonstrating that sildenafil use is not associated with an increased risk for cardiovascular events [13]. Patients with known coronary artery disease using nitrates are more at risk of developing MI after receiving sildenafil as this could cause prolonged and exaggerated vasodilatation and hypotension [4], though the so-called coronary steal phenomenon has not been documented in animal models [5].

On the contrary, sildenafil-associated MI is rarely seen in patients without previous history of coronary artery disease [2]. Our patient is one such rare case. Notably, our patient's chest pain began shortly after taking sildenafil and before any attempt at sexual activity, thus eliminating the physical stress of sexual intercourse as the precipitating cause. Although the patient had a blood pressure of $80 / 54 \mathrm{~mm} \mathrm{Hg}$ at presentation, nevertheless he was bradycardic. A possible explanation for the lack in heart rate response is that our patient had the unusual problem of a sinus node that was supplied by the circumflex coronary artery (the ECG is consistent with a true posterior and inferior infarction). Probably the mechanism of MI was hypotension acting as a second hit factor in the pres- ence of a silent $70 \%$ coronary artery occlusion, since sildenafil-induced hypotension alone is not known to produce MI $[5,6]$. It is possible that the patient may have had an idiosyncratic vasodilatory response to sildenafil, as evidenced by flushing, vomiting and low blood pressure at presentation. The Naranjo score was $6 / 13$, indicating a probable cause-and-effect relationship between sildenafil and the MI in our patient [7].

Although this case does not establish a definite correlation between sildenafil intake and development of acute MI, however, given its mechanism of action and the temporal relationship between ingestion of sildenafil and the onset of chest pain, the occurrence of MI in our patient was probably more than coincidental.

Generally sildenafil is a safe drug and may even have potentially beneficial, albeit mild therapeutic effects. Risk stratification guidelines have been developed to predict the likelihood of a significant coronary event from sexual activity or from the treatment of erectile dysfunction with PDE5 inhibitors in men, and these guidelines could be a useful tool for assessing the need for further evaluation for coronary artery disease prior to initiation of PDE5 inhibitor therapy.

\section{Conclusion}

This report shows a rare sildenafil-associated MI in a nitrate-free patient without previous history of coronary artery disease. Physicians should be aware of this possibility.
References
1 Mittleman MA, Glasser DB, Orazem J: Clinical trials of sildenafil citrate (Viagra) demonstrate no increase in risk of myocardial infarction and cardiovascular death compared with placebo. Int J Clin Pract 2003;57: 597-600.

-2 Mittleman MA, Maclure M, Glasser DB: Evaluation of acute risk for myocardial infarction in men treated with sildenafil citrate. Am J Cardiol 2005;96:443-446.

- 3 Kekilli M, Beyazit Y, Purnak T, Dogan S, Atalar E: Acute myocardial infarction after sildenafil citrate ingestion. Ann Pharmacother 2005;39:1362-1364

4 Iglesias ML, Jerico C, Skaf E, Pedro-Botet J: Sildenafil and coronary artery disease. BJU Int 2003;92:824-825.
5 Reffelmann T, Kloner RA: Therapeutic potential of phosphodiesterase 5 inhibition for cardiovascular disease. Circulation 2003; 108:239-244.

6 6 Kostis JB, Jackson G, Rosen R, Barrett CE, Billups K, Burnett AL, Carson C 3rd, Cheitlin M, Debusk R, Fonseca V, Ganz P, Goldstein I, Guay A, Hatzichristou D, Hollander JE, Hutter A, Katz S, Mittleman M, Montorsi F, Montorsi P, Nehra A, Sadovsky R, Shabsigh R: Sexual dysfunction and cardiac risk (the Second Princeton Consensus Conference). Am J Cardiol 2005;96:85M-93M.

$\checkmark 7$ Naranjo CA, Busto U, Sellers EM, Sandor P, Ruiz I, Roberts EA, Janecek E, Domecq C, Greenblatt DJ: A method for estimating the probability of adverse drug reactions. Clin Pharmacol Ther 1981;30:239-245. 